\title{
Sistematização dos conhecimentos propostos pelo apostilado do Sistema Positivo de ensino médio para a leitura e a interpretação
}

\author{
Sílvio Ribeiro da Silva \\ Universidade Federal de Goiás -Jataí \\ Universidade Federal do Mato Grosso \\ shivonda@gmail.com
}

\section{Resumo}

Neste trabalho, apresento dados de uma pesquisa, inserida no campo da Linguística Aplicada, cuja análise objetivou identificar que capacidades de leitura são desenvolvidas a partir da abordagem teórico-metodológica dada à leitura e à interpretação de gêneros do discurso pelo apostilado do sistema Positivo para o Ensino Médio. Para a análise dos dados, procedo a uma descrição dos parâmetros teórico-metodológicos apresentados pelo apostilado, bem como à análise das seções nas quais as atividades de leitura e interpretação são apresentadas aos alunos, usando para a sistematização dos dados algumas capacidades colocadas em prática durante o ato de leitura. A análise dos dados indica que, para a construção do conhecimento acerca da leitura e da interpretação de gêneros do discurso, o apostilado apresenta um apego excessivo à prática da compreensão, deixando de lado a prática da interpretação. Nota-se, ainda, a total desarticulação dos eixos de ensino leitura/interpretação, produção oral e escrita e análise linguística. Além disso, os conhecimentos propostos pelo material não permitem que se construa uma reflexão sobre a natureza e o funcionamento da linguagem e, em especial, sobre a língua materna.

Palavras-chave: leitura; interpretação; material didático; ensino de língua materna

\begin{abstract}
In this paper, I present data from a research, included in the field of Applied Linguistics, that aimed to identify which reading skills are developed from the theoretical and methodological approach given to reading and interpretation of speech genres by sistema Positivo's book to high school. For data analysis, I proceed to a description of the theoretical and methodological parameters presented by the textbook, as well as the analysis of the sections in which the activities of reading and interpretation are presented to students, using to data
\end{abstract}

Horizontes de Linguística Aplicada, ano 10, n. 2, jul./dez. 2011 
analysis some skills that are put into practice during the act of reading. Data analysis indicates that, for the construction of knowledge about the reading and interpretation of speech genres, the textbook presents an excessive attachment to the practice of comprehension, leaving aside the practice of interpretation. Data analysis also shows the total disconnectedness of the teaching reading/interpretation, speaking and writing productions, and linguistic analysis' axes. In addition, the knowledge offered by the material does not allow a reflection on the nature and functioning of language and, in particular, the mother tongue.

Keywords: reading; interpretation; teaching materials; mother language teaching

\section{Considerações iniciais}

O foco central deste estudo ${ }^{1}$ é a leitura no Ensino Médio (EM). Um estudo dessa natureza torna-se relevante por conta das capacidades leitoras limitadas apresentadas pelos egressos do EM nos exames e avaliações do governo federal. Os baixos resultados se devem, muitas das vezes, a uma prática de ensino de leitura incapaz de formar um leitor competente, associando a isso a abordagem dada pelo material didático aos eixos de ensino. Ao observar como um sistema de ensino privado aborda a prática da leitura, será possível conhecer melhor essa prática que circula no ambiente escolar das unidades que o seguem.

Como a maioria dos sistemas da rede privada, o que observo aqui usa apostilado, que se opõe ao livro didático por este apresentar um padrão fixo. As escolas que usam sistema de apostilado categorizam seu material de forma genérica, apresentando-o como lista de livros.

A palavra apostila estrutura-se em illa- dedução, conclusão, inferência, e em post- após, depois. Carvalho Neto (2004) diz que apostila poderia significar aquilo que foi escrito, registrado posteriormente a um fato ou processo.

\footnotetext{
${ }^{1}$ Este estudo foi contemplado com bolsa PIBIC/CNPq-2010/2011 e seus resultados contribuem com os estudos realizados dentro do Projeto Integrado de Pesquisa Livro Didático de Língua Portuguesa - produção, perfil e circulação (UNICAMP/CNPq), bem como do Grupo de Estudos da Linguagem: análise, descrição e ensino (UFG/CNPq).

Horizontes de Linguística Aplicada, ano 10, n. 2, jul./dez. 2011
} 
O surgimento do apostilado ocorreu na década de 1950. Inicialmente foi feito para ser utilizado em cursos preparatórios para concursos e exames de admissão. Posteriormente passou a ser um método de ensino específico, objetivando preparar as pessoas para o vestibular (TREDICI, 2007). Somente no final da década de 1990 é que houve a adesão conjunta das escolas privadas a esse sistema. Essa adesão se deu pelo fato de as escolas se mostrarem preocupadas em atender aos anseios de pais e alunos com a concorrência acirrada do vestibular (LIMA, 2006) e com o baixo nível de qualidade dos livros didáticos naquela época.

Por mais que o professor seja o grande responsável pela formação do aluno em sala de aula, não há dúvida de que o material didático utilizado por esse aluno exerce forte influência no aprendizado. Segundo o Guia do Programa Nacional do Livro do Ensino Médio (BRASIL, 2008) ${ }^{2}$, em momento algum o material didático é um substituto do professor ou de suas experiências pedagógicas. No entanto, pode ser um bom referencial para ampliar os trabalhos em sala de aula.

O material didático (apostilado) adotado pelas escolas da rede privada de ensino não passa por nenhum tipo de avaliação oficial antes de ser usado em sala de aula. Pelo fato desse material refletir no trabalho real desenvolvido pelo professor, indicando ainda a concepção de ensino da rede/sistema que o elaborou, é que se torna importante analisar a apresentação de uma proposta de ensino a ser efetivado nas escolas. Além disso, por mais que o governo federal realize a avaliação do material didático e encaminhe para todas as escolas públicas do país esse material gratuitamente, tem sido relevante o número de escolas públicas que vem optando por adotar apostilas ${ }^{3}$. Por conta disso,

2 A partir do ano de 2011, o Fundo Nacional de Desenvolvimento da Educação (FNDE) adotou a mesma nomenclatura da avaliação do Ensino Fundamental para o Ensino Médio: Programa Nacional do Livro Didático (PNLD).

${ }^{3}$ Quando o material didático não passa por processo de avaliação, corre-se o risco de surpresas desagradáveis, como o que aconteceu no estado de São Paulo em 2010. Livros didáticos de inglês distribuídos pela Secretaria da Educação (não avaliados pelo programa de avaliação do governo federal) para cerca de 15 mil alunos de 4 mil escolas indicavam em suas páginas um site de aprofundamento do EM com links para jornais estrangeiros. Ao acessar o endereço eletrônico, no entanto, o que o adolescente

Horizontes de Linguística Aplicada, ano 10, n. 2, jul./dez. 2011 
acompanhar a abordagem teórico-metodológica do sistema de apostilados se torna uma tarefa pertinente à universidade.

\section{Leitura: atividade fundamental para o desenvolvimento do(s) letramento(s) ${ }^{4}$}

Segundo Cagliari (1997), saber ler é mais importante do que saber escrever. Na opinião do autor, se o aluno não conseguir êxito nas outras habilidades desenvolvidas pela escola, mas for um bom leitor, já será um grande feito. Realmente as palavras de Cagliari fazem muito sentido. A leitura acompanha o indivíduo em muitas de suas situações de interação durante a vida. A leitura é "a extensão da escola na vida das pessoas. [...] A leitura é uma herança maior do que qualquer diploma" (CAGLIARI, 1997, p. 148).

Essas afirmações de Cagliari vêm ao encontro da preocupação com a necessidade de se formar um indivíduo reflexivo, crítico, capacitado para posicionar-se diante do mundo por meio da habilidade de expressar suas opiniões, o que pode ser, perfeitamente, desenvolvido nas atividades de leitura. Em se tratando do aspecto crítico e reflexivo do aluno o qual deve ser desenvolvido, a LDB (BRASIL, 1996) coloca, no Art. 35, item III, que o EM tem como uma de suas finalidades "o aprimoramento do educando como pessoa humana, incluindo a formação ética e o desenvolvimento da autonomia intelectual e do pensamento crítico". Essa preocupação com a criticidade torna-se ainda mais pertinente quando se trata de um país excludente, desigual e desprovido de posicionamentos críticos, como é o caso do Brasil.

A leitura é uma atividade de extrema importância na vida de um aluno. Ela é tida como ponto de partida para a aquisição de

encontrava eram mulheres lendo notícias em voz alta enquanto se despiam (ISTOÉ, 2010, p. 29).

4 Atualmente, vigora na academia o amadurecimento da ideia de que existem letramentos, e não simplesmente letramento. Isso tem a ver com o fato de que várias das atividades que desenvolvemos exigem o uso de determinados domínios. São esses domínios que ultimamente têm sido chamados de letramentos, multiletramentos ou letramentos múltiplos (ROJO, 2009). 
conhecimento e para a ampla socialização do ser. Quando a escola não ensina o aluno a ler e a interpretar o que leu, ela deixa de cumprir sua função enquanto instância de desenvolvimento de letramento(s), porque acaba formando autômatos ao invés de pessoas capazes de usar a língua nas diferentes situações em que se requer o seu uso. Assim, $o(s)$ letramento(s) deixa(m) de ser favorecido(s).

$\mathrm{O}$ trabalho com atividades de leitura e interpretação envolve várias etapas. Ler um texto é uma atividade que consiste em não apenas decodificar seus sinais; é preciso que o leitor atribua sentido ao que lê, sentido este dado por um sujeito sócio-historicamente constituído. $\mathrm{O}$ conhecimento anterior e as experiências passadas funcionam como base para a compreensão da leitura. Isso porque, muito antes de a criança dominar o ato da leitura, ela já tem experiências com o mundo e com a língua.

O dever da escola então é fazer com que o aluno aprenda o que não sabe. $\mathrm{O}$ que precisa aprender é a ler e interpretar a palavra, mas não a palavra isolada. A importância no ensino adequado da leitura e da interpretação da palavra reside no fato de ela estar, segundo Bakhtin e Volochinov (1981, p. 41), penetrada "literalmente em todas as relações entre os indivíduos, nas relações de colaboração, nas de base ideológica, nos encontros fortuitos da vida cotidiana, nas relações de caráter político, etc."

A escola deve, então, ensinar ao aluno a forma adequada de usar a palavra, uma vez que ela pode transformá-lo, dar uma nova dimensão à sua consciência, o que acaba por possibilitar-lhe uma reflexão sobre a sua realidade e a maneira de agir sobre ela. $\mathrm{Na}$ escola, o aluno deverá saber como recorrer a diferentes materiais impressos para atender a diferentes necessidades.

Para o ato de ler ser desenvolvido, é preciso que o sujeito leitor faça uso de algumas habilidades, ou capacidades leitoras, conforme Rojo (2004), levando em conta, ainda, o(s) objetivo(s) da leitura ${ }^{5}$ e as práticas de letramento envolvidas no ato. Para a autora, essas

\footnotetext{
${ }^{5}$ Dentre esses objetivos, segundo Solé (1998), temos: ler para que encontrar dados num dicionário ou lista telefônica; ler para seguir instruções determinadas dadas por manuais de instrução, bulas de remédio ou prospectos de evento; ler para aumentar o conhecimento acerca de determinado tema, estabelecendo relações entre o que já se sabe e aquilo que está sendo aprendido, por exemplo.
}

Horizontes de Linguística Aplicada, ano 10, n. 2, jul./dez. 2011 
capacidades são: a) de decodificação, b) de compreensão, c) de apreciação e réplica do leitor em relação ao texto.

Para colocar a primeira capacidade em uso, o texto precisa ser caracterizado como fonte única de sentido; uma postura que provém de uma visão estruturalista e mecanicista da linguagem, ligada diretamente à ideia da língua como mero instrumento de comunicação. $\mathrm{O}$ foco ser voltado especificamente para o texto é algo a ser considerado, tendo em vista que é sobre o texto que a atividade de leitura vai se dar (INDURSKY, 2010). Porém, sabemos que o foco central incidir apenas sobre o texto é tão somente uma prática inicial para uma leitura eficiente, sendo o ato de ler muito mais que isso.

No uso dessa capacidade, a leitura "deve dar conta das relações linguísticas que se estabelecem entre os diferentes elementos constituintes do texto" (INDURSKY, 2010, p. 165). Nesse sentido, a leitura se dá sobre uma superfície linguística de um texto perfeitamente acabado e que se apresenta completamente fechado.

Já a segunda capacidade é colocada em uso quando o leitor é o responsável pela construção do sentido daquilo que lê. Assim, um mesmo texto varia de visões dependendo do leitor. Como tempo e espaço situam cada leitor de diferentes maneiras, conclui-se que leitores diferentes farão leituras também diferentes em outra época, ainda que se repita a leitura de um mesmo texto (INDURSKY, 2010). As experiências prévias de que ele dispõe serão as responsáveis pela compreensão do que se lê. $O$ texto apresenta lacunas a serem preenchidas pelo leitor com o seu conhecimento de mundo, por exemplo. Para essa capacidade ser colocada em uso, é preciso saber ler o mundo, dando sentido a ele.

A terceira capacidade é exigida quando, por exemplo, ao ler, sente-se prazer, deixa-se enlevar e aprecia-se o belo na forma da linguagem. Os textos lidos são, naturalmente, marcados ideologicamente, já que, segundo Bakhtin e Volochinov (1981), a ideologia é um reflexo das estruturas sociais, e essas marcas ideológicas exigirão uso da capacidade de apreciação e réplica. Essa capacidade faz com que o leitor perceba o funcionamento ideológico dos vários tipos de discurso, observe a força ilocutória presente em cada texto, além de fazê-lo consciente de que a linguagem é uma forma 
de atuar, de influenciar, de intervir no comportamento alheio, de modo que é por meio dela que as pessoas atuam umas sobre as outras.

Na acepção da apreciação e réplica aplicadas à leitura, o leitor pode "dialogar" com o texto, concordando ou replicando com aquilo que está sendo dito, praticando um ato de interlocução com o texto.

\section{Considerações preliminares sobre os dados}

Antes de dar início às considerações acerca dos dados em análise, convém mencionar que, ao selecionar recortes de exemplos para ilustrar as considerações, optei por aqueles que dão indício de um trabalho positivo desenvolvido pelo apostilado. Tal opção se deve ao fato de que é comum encontrarmos diversos estudos que abordam os pontos negativos da proposição de atividades apresentadas por materiais de ensino e livros didáticos, sendo pouco comuns discussões sobre a positividade dessas proposições. Seguindo a estratégia de apontar as negatividades, penso que este trabalho pouco contribuiria com as discussões acerca do tema. No entanto, ao longo da análise e nas considerações finais, faço alguns apontamentos críticos em relação a pontos que poderiam ser melhorados.

Para a análise dos dados, uso como categorias para sistematização dos mesmos as capacidades colocadas em prática durante o ato de leitura, apresentadas anteriormente. Bem sei que pode acontecer de as categorias serem limitadas, tendo em vista que, provavelmente, pelo fato de o material do ensino privado não passar por processos de avaliação formal, não é feito com base naquilo que se espera de um material quando é avaliado. Porém, sei que o uso de categorias permite uma melhor sistematização dos dados.

O sistema de apostilado Positivo para o EM é organizado de forma que os alunos recebam, por ano, quatro apostilas, uma por bimestre, somando no final dos três anos do EM um total de 12 exemplares.

Cada volume é organizado por capítulos, sendo que cada um deles é dividido em seções nomeadas: "Tecendo Ideias"; "Entrando na Rede"; "Nas Malhas do Texto"; "Comparando"; "Relacionando"; "Conhecendo a Teoria"; "Aplicando a Teoria" e "Leitura e Produção 
Textual". As atividades de leitura e interpretação, segundo o próprio material, são apresentadas nas seções: "Tecendo Ideias";; "Entrando na Rede"; "Comparando"8 e "Relacionando".

Em se tratando do número total de atividades de leitura e interpretação apresentado nas três séries, em cada uma das seções indicadas anteriormente, tem-se o seguinte.

Tabela 1. Atividades de leitura no geral

\begin{tabular}{ll}
\hline Seção & Total de atividades \\
\hline Tecendo Ideias & 52 \\
Entrando na Rede & 150 \\
Comparando & 62 \\
Relacionando & 85 \\
\hline Total geral & $\mathbf{3 4 9}$ \\
\hline
\end{tabular}

Pelos números quantitativos apresentados, nota-se que a seção "Entrando na Rede" é a mais privilegiada pelo apostilado. Privilegiar a seção "Entrando na Rede" é um bom indicativo, tendo em vista que, segundo os autores, essa seção envolve questões de compreensão e desenvolvimento de leitura.

Em se tratando do uso das capacidades de leitura usadas aqui como categorias de análise, a tabela 2 exibe os dados quantitativos percentuais para cada seção.

Por questão de espaço, apresentarei aqui considerações qualitativas apenas acerca da capacidade de leitura mais praticada pelo apostilado na seção em que aparecem mais atividades, sendo, portanto, essa capacidade a de compreensão na seção "Entrando na Rede". Apesar de a capacidade de apreciação e réplica ser aquela que mais colabora para a formação de um leitor crítico e reflexivo, não é ela a

${ }^{6}$ Espaço para a troca de ideias, experiências e conhecimentos prévios sobre um determinado assunto.

${ }^{7}$ Antecede a leitura de um texto. Envolve questões de compreensão e desenvolvimento de habilidades de leitura.

8 Apresentação de um novo texto, cuja leitura por objetivo um trabalho de diferenciação entre linguagem, função, gêneros ou pontos de vista, ou seja, o enfoque maior, aqui, está nas diferenças.

${ }^{9}$ Introduz um novo texto com o objetivo de proporcionar um trabalho complementar ou de ampliação do sentido do texto principal da unidade. 
mais privilegiada pelo material. Assim, apresentando o trabalho feito pela capacidade mais praticada na seção com mais atividades, penso que será possível ao leitor concluir se a forma como o material em discussão lida com a leitura será contributivo ou não a esse aluno em formação.

Tabela 2. Valores percentuais conforme capacidade de leitura e seção

\begin{tabular}{llllll}
\hline \multicolumn{2}{c}{ Decodificação } & \multicolumn{2}{c}{ Compreensão } & \multicolumn{2}{c}{ Apreciação e réplica } \\
\hline Seção & VP $^{1 \mathbf{1 1}}$ & Seção & VP & Seção & VP \\
\hline TI & $0 \%$ & TI & $50 \%$ & TI & $50 \%$ \\
ER & $0 \%$ & ER & $92 \%$ & ER & $8 \%$ \\
CO & $0 \%$ & CO & $92 \%$ & CO & $8 \%$ \\
RD & $0 \%$ & RD & $82 \%$ & RD & $18 \%$ \\
\hline
\end{tabular}

\section{Direcionando o olhar sobre os dados}

Nesta parte, apresento e analiso um exemplo de cada série que ilustra de que forma o apostilado em discussão trabalha o desenvolvimento da capacidade de compreensão do aluno na seção em observação. Mesmo sendo apresentado apenas um exemplo para cada série, penso que o leitor, ainda assim, terá condições de visualizar como o apostilado trabalha a capacidade de leitura em destaque, já que as atividades propostas ao aluno as quais desenvolvem essa capacidade seguem o mesmo estilo.

Convém apresentar, antes, algumas considerações que o sistema Positivo traz sobre a leitura e a interpretação, no intuito de trazer à tona a ideologia, ou a concepção, do material acerca desse eixo de ensino. Segundo os proponentes do material (DIAS; LIMA, 2008, p. 2, livro do professor), o embasamento pelo qual as atividades passam é o de origem interacionista e discursiva, fugindo da abordagem vinculada à língua como instrumento de comunicação, abordagem esta presente ainda em algumas propostas de ensino. Nesse sentido, o material se propõe a trabalhar a leitura buscando

${ }^{10} \mathrm{TI}=$ Tecendo ideias; $\mathrm{ER}=$ Entrando na rede; $\mathrm{CO}=$ Comparando; $\mathrm{RD}=$ Relacionando.

${ }^{11} \mathrm{VP}=$ valor percentual.

Horizontes de Linguística Aplicada, ano 10, n. 2, jul./dez. 2011 
desenvolver habilidades que vão além daquelas que levam a perceber apenas o que está dito na linearidade do texto. O que é apresentado ao aluno, segundo o próprio sistema, é um trabalho que o leva a atribuir sentidos com base em sua história e em suas experiências, perpassando pelo contexto sócio-histórico e político.

Os proponentes do material (DIAS; LIMA, 2008, p. 3, livro do professor) afirmam que o trabalho com a leitura precisa ganhar um espaço privilegiado no ensino e na aprendizagem de língua materna, já que é por meio dessa prática que se garante ao aluno a autonomia necessária para buscar os saberes construídos historicamente pela humanidade.

Em se tratando do espaço dado pelo material para a abordagem da leitura, nota-se que existe certa inconsistência entre aquilo que se diz e aquilo que se pratica. Na tabela 1 apresentada anteriormente, temse o montante de atividades de leitura e interpretação apresentadas ao aluno nas seções que o próprio sistema afirma usar para a prática desse eixo. Como pôde ser visto na referida tabela, o total de atividades de leitura e interpretação é de 349. Somando-se o total de atividades de todas as seções, incluindo as que não são específicas de leitura e interpretação, chega-se ao valor de 1.090 atividades. Em se tratando de valores percentuais em relação a esse montante, o número de atividades destinadas ao desenvolvimento das capacidades de leitura e interpretação do aluno é de apenas $32 \%$, sendo o restante destinado aos demais eixos, excetuando-se a oralidade.

Outro aspecto que é preciso mencionar antes de se direcionar o olhar sobre os dados diz respeito aos gêneros que são apresentados ao aluno. Os proponentes do material (DIAS; LIMA, 2008, p. 1, livro do professor) dizem explorar uma diversidade de gêneros. O trabalho com a diversidade de gêneros traz inúmeros benefícios ao aluno num programa de ensino de língua. Segundo Dolz, Noverraz e Schneuwly (2004), para que a diversidade das capacidades de linguagem seja desenvolvida com êxito, devem ser trabalhados com o aluno gêneros pertencentes a agrupamentos diferentes ${ }^{12}$, reservando-se espaço e não

\footnotetext{
12 Segundo Dolz e Schneuwly (2004), agrupamento se refere à montagem de sequências didáticas que tragam determinado número de gêneros agrupados de acordo com os aspetos tipológicos e capacidades de linguagens dominantes no gênero. $\mathrm{Na}$ 96

Horizontes de Linguística Aplicada, ano 10, n. 2, jul./dez. 2011
} 
se negligenciando o ensino-aprendizagem da modalidade oral ${ }^{13}$. Essa escolha também será efetuada em função dos objetivos do programa de cada série e do grau de dificuldade para os alunos.

Em relação a essa consideração sobre a variedade de gêneros a ser trabalhada com o aluno, o apostilado traz os seguintes para a leitura e a interpretação por série ${ }^{14}$.

Tabela 3. Gêneros apresentados ao aluno por série

\begin{tabular}{l|lll}
\hline & $\mathbf{1}^{\mathrm{a}}$ série & $\mathbf{2}^{\mathrm{a}}$ série & $\mathbf{3}^{\mathrm{a}}$ série \\
\hline Total de gêneros & 9 & 9 & 6 \\
\hline
\end{tabular}

As indicações sobre a forma composicional dos gêneros propostos são feitas após a apresentação do texto específico para leitura e interpretação. Essas indicações estão na seção "Nas Malhas do Texto", seção que, segundo o próprio apostilado (DIAS; LIMA, 2008, p. 3, livro do professor), destina-se ao estudo da gramática do texto, englobando atividades que objetivam a análise e a sistematização de conhecimentos relativos ao texto, ao gênero, à tipologia e aos recursos discursivos. É nessa seção que o apostilado traz a definição do gênero do texto apresentado na seção específica de leitura, além de alguns comentários que objetivam situar o gênero em seu contexto de circulação. Como essas considerações não aparecem na seção específica de leitura, penso que o material deixa de oferecer importantes contribuições ao aluno para que este crie familiaridade com o gênero. Além disso, não são fornecidas, em nenhum momento, informações sobre as condições de produção dos textos apresentados para leitura.

Os gêneros apresentados ao aluno são separados por temas, totalizando nove temas para a $1^{\mathrm{a}}$ série, dez para a $2^{\mathrm{a}}$ e oito para a $3^{\mathrm{a}}$. Pela disposição temática, nota-se que vários deles suscitam o diálogo e o debate. Porém, como dito anteriormente, o sistema Positivo ignora o

proposta dos autores, esses aspectos tipológicos são narrar, relatar, argumentar, expor e descrever ações.

${ }^{13}$ A respeito da consideração dos autores acerca do trabalho com a modalidade oral, cabe comentar que o sistema Positivo menospreza o desenvolvimento das capacidades vinculadas ao oral.

${ }^{14}$ Pela limitação do espaço, não tenho como apresentar os gêneros propostos ao aluno para leitura e interpretação.

Horizontes de Linguística Aplicada, ano 10, n. 2, jul./dez. 2011 
eixo da oralidade nas atividades apresentadas ao aluno ao longo das três séries do EM. Outro aspecto que pode ser percebido em relação ao tratamento temático do apostilado diz respeito a uma ausência de temas que circulam em contextos culturais diferentes, como rural e doméstico, por exemplo. Além disso, apesar de apresentar um considerável número de temas, estes são abordados de maneira superficial nas atividades.

Um comentário que acredito caber aqui ainda em relação ao aspecto temático diz respeito à ausência de temas passionais (DOLZ; SCHNEUWLY; DE PIETRO, 2004, p. 262), tais como pena de morte e aborto, uma vez que bloqueiam qualquer possibilidade de evolução das posições ou mesmo da discussão, além de apresentarem "o inconveniente de impedir que os alunos possam, num certo momento, distanciarem-se do debate e endossarem uma postura de aprendizagem". Foi positivo também a ausência de temas controversos, como racismo e preconceito. Para Golder (1996), temas assim podem não se prestar ao discurso numa instituição como a escola, já que esta tem uma natureza ideológica e um forte compromisso com a ética, não aceitando em seu espaço a defesa da discriminação racial ou do preconceito. Sendo assim, a controvérsia do tema acabaria sendo eliminada.

Concluídas as considerações iniciais sobre a abordagem do apostilado acerca dos gêneros apresentados ao aluno, passo a apresentar um exemplo ilustrativo de cada série. Os exemplos ilustrativos foram escolhidos por serem os mais representativos dentro do universo de ocorrências de atividades cujo foco central é o desenvolvimento da capacidade de compreensão.

$\mathrm{O}$ texto apresentado para leitura, referente ao primeiro exemplo ilustrativo, é um conto fantástico de Ivan Ângelo, intitulado Talismã (DIAS; LIMA, 2008, p. 18-19). Após o texto, aparecem oito atividades de interpretação, divididas em subjetivas e objetivas, sendo foco central das questões explorar com o aluno o sentido de palavras e expressões pouco usuais no vocabulário cotidiano e que aparecem no texto. Uma dessas questões que ilustra o uso da capacidade de compreensão é a que mostro no quadro 1.

A pergunta apresentada é do tipo textualmente implícita, isto é, para se chegar a ela é necessário o uso de inferências por parte do leitor 
a partir de pistas oferecidas pelo texto. Seguindo essas pistas, o leitor consegue construir a compreensão, apresentando uma resposta ao menos parcialmente elaborada.

Quadro 1. Exemplo ilustrativo $-1^{\mathrm{a}}$ série

\begin{tabular}{|c|c|}
\hline Série & Exemplo ilustrativo - Questão 2, p. 20 \\
\hline $1^{\mathrm{a}}$ & $\begin{array}{l}\text { No segundo parágrafo do texto, encontramos os termos "frágil" e } \\
\text { "despetalável" em oposição a "taludo" e "viçoso". É possível } \\
\text { inferir o que significam essas últimas palavras, analisando-as em } \\
\text { relação às primeiras? }\end{array}$ \\
\hline
\end{tabular}

Nesse exemplo, trabalha-se com a inferência contextual como estratégia de compreensão. Nesse tipo de estratégia, o leitor precisa descobrir, pelo contexto imediato do texto (a frase, o período, o parágrafo), e pelo significado anteriormente já construído, um novo significado para o termo até então desconhecido. Dessa forma, a leitura é vista como um processo em que deve ser construído um sentido como resultado de um processamento de conhecimentos provindos diretamente do material impresso, de conhecimentos indiretamente extraídos do texto via inferenciação e de outros conhecimentos pertencentes à situação de produção e recepção do texto (POERSCH, 1990).

Da forma como a atividade é apresentada, dá-se a entender que a figura do professor será importante para o êxito da mesma, uma vez que a abordagem vocabular apresentada pela questão por si só pode não contribuir para a compreensão, como também pouco colaborar para o enriquecimento do vocabulário do aluno. Assim, talvez o professor pudesse apresentar outros casos em que as palavras seriam usadas, considerando aspectos como o metafórico ou o figurado, por exemplo. Ao professor poderia caber, ainda, a tarefa de orientar os alunos a entender as escolhas lexicais feitas pelo autor, associando-as ao campo semântico do texto em questão.

Ainda em relação à questão inferencial favorecida pela atividade em observação, cabe mencionar Marcuschi (2003), quando diz que ser uma alternativa excepcional de trabalhar a compreensão quando ocorrem perguntas que exigem a reunião de informações para serem respondidas, ou afirmações que, para serem justificadas, necessitam que o leitor siga alguns passos. $\mathrm{Na}$ atividade em

Horizontes de Linguística Aplicada, ano 10, n. 2, jul./dez. 2011 
observação, o leitor percebe que a resposta a ela não se acha diretamente inscrita no texto. A inferência requerida pela atividade fará com que o aluno produza informações novas a partir de informações previamente ofertadas, sejam elas textuais ou não (MARCUSCHI, 2003).

O texto apresentado para leitura que escolhi para ilustrar a $2^{\mathrm{a}}$ série é uma resenha sobre uma coletânea de textos de Ruy Castro intitulada Ungáua (DIAS; LIMA, 2008, p. 2-3). Antes do texto, na seção "Tecendo Ideias", o apostilado traz uma passagem de Schopenhauer ${ }^{15}$, retomada depois numa das nove questões de interpretação apresentadas para o aluno que mostro no quadro 2.

Quadro 2: Exemplo ilustrativo $-2^{\mathrm{a}}$ série

\begin{tabular}{|ll|}
\hline Série & Exemplo ilustrativo - Questão 9, p. $\mathbf{4}$ \\
\hline $2^{\text {a }}$ & $\begin{array}{l}\text { Releia o penúltimo parágrafo do texto e compare-o com a citação de } \\
\text { Schopenhauer, que fecha a seção “Tecendo Ideias". Que relações } \\
\text { podem ser estabelecidas entre os dois trechos? }\end{array}$ \\
\hline
\end{tabular}

A pergunta apresentada não oferece ao aluno a resposta em nenhuma parte do texto, havendo a necessidade de elaborá-la por completo. $\mathrm{O}$ aluno terá que cruzar informações dadas pelo texto, mas indo além para conseguir construir o sentido daquilo que leu. Segundo Rojo (2004), ao longo de uma leitura, é comum ao leitor comparar informações de várias ordens, advindas do texto, de outros textos, de seu conhecimento de mundo, de maneira a construir os sentidos do texto que está lendo. $\mathrm{Na}$ atividade em destaque, a comparação a ser feita será entre dois textos, atividade importante para medir a relevância das informações que deverão ser retidas.

Essa atividade de relação proposta pela questão, se bem orientada, é bastante contributiva para a construção da compreensão, tornando o ato de ler mais ativo e produtivo, estimulando o aluno a construir relações de intertextualidade e ajudando-o a compreender melhor o que leu. O material didático poderia ter aproveitado a questão para oportunizar ao aluno o diálogo oral com os colegas, colocando em discussão o que alguns perceberam sobre a relação requerida, se houve

\footnotetext{
${ }^{15}$ A passagem é "Quem quer que tenha algo verdadeiro a dizer se expressa de modo simples. A simplicidade é o selo da verdade". 
diferença entre a apresentação dessa relação, de que forma isso foi feito e como se chegou a essa diferença. Porém, como dito anteriormente, o eixo da oralidade é desprezado pelo material, sendo a escrita a prática comumente solicitada.

Aqui, mais uma vez, acredito ser importante a participação do professor, já que o aluno pode ter dificuldade para fazer a tal relação proposta pela questão, pois esse tipo de atividade é pouco comum nas práticas letradas cotidianas. Como o livro do professor não traz nenhuma orientação nesse sentido, provavelmente porque os proponentes do material acreditam que a atividade de relacionar os textos seja corriqueira, optar pela orientação ao aluno caberá a cada professor.

O texto apresentado para leitura, cuja atividade ilustra o que é apresentado ao aluno da $3^{\text {a }}$ série, é um recorte de um texto do linguista Sírio Possenti, apresentado em seu livro intitulado $A$ cor da língua $e$ outras croniquinhas de linguística (DIAS; LIMA, 2008, p. 3). Em seguida, aparecem cinco questões, sendo duas subjetivas e as demais objetivas. Uma das subjetivas é exibida no quadro 3.

Quadro 3. Exemplo ilustrativo $-3^{\mathrm{a}}$ série

\begin{tabular}{|ll|}
\hline Série & Exemplo ilustrativo - Questão 2, p. $\mathbf{4}$ \\
\hline $3^{\text {a }}$ & $\begin{array}{l}\text { Apesar de estar adequado ao registro formal da linguagem escrita, o } \\
\text { texto utiliza palavras e expressões próprias do registro oral e } \\
\text { informal. Cite dois exemplos. }\end{array}$ \\
\hline
\end{tabular}

A questão pede ao aluno que retorne ao texto para identificar algo solicitado, sendo uma pergunta do tipo textualmente explícita. Para isso, ele terá que localizar a informação e copiá-la. Rojo (2004) nos diz que em certas práticas de leitura é preciso estar constantemente buscando e localizando informação relevante para armazená-la e, posteriormente, reutilizá-la de maneira reorganizada. Trata-se de uma estratégia básica de muitas práticas de leitura, mas também não opera sozinha, sem a contribuição de outras.

No caso da questão em observação, o aluno só será capaz de identificar as expressões solicitadas se souber do que se trata registro oral e informal. Assim, não caberá a ele apenas a decodificação, mas um passo além. Nesse sentido, a questão estimula o aluno a saber buscar informações relevantes e abandonar as periféricas, deixando de Horizontes de Linguística Aplicada, ano 10, n. 2, jul./dez. 2011 
lado uma quantidade de informações como requisito para encontrar a necessária. Essa prática traz a vantagem de aproximar a leitura de um contexto de uso real (em várias situações é preciso localizar informação específica num universo grande de informações), dando ao aluno a oportunidade de trabalhar a rapidez na leitura.

Faltou à atividade explorar melhor as variações de registro, especialmente ligadas ao uso oral da linguagem ${ }^{16}$. A questão coloca que o oral é informal, concretizado em gêneros primários no dizer de Bakhtin (1979). Porém, sabemos que o oral pode ser formal, concretizado em gêneros secundários, dependendo da esfera e do interlocutor a quem o gênero se dirige. Caberia, mais uma vez, ao professor aproveitar a oportunidade para problematizar essas questões com o aluno, sem teorizar aspectos bakhtinianos, naturalmente. Porém, não existe qualquer orientação ao professor nesse sentido.

\section{Considerações finais}

Ao longo deste estudo, discuti que capacidades de leitura são trabalhadas com os alunos a partir da abordagem da leitura e da interpretação de um sistema de apostilado da rede privada de EM. Pôde ser visto na análise quantitativa que a maior parte das atividades é centrada no desenvolvimento da capacidade de compreensão, deixando de lado a capacidade mais pertinente, que seria a de apreciação e réplica.

Faltou ao material apresentar atividades voltadas diretamente para o desenvolvimento de capacidades implicadas na leitura proficiente, como o resgate de aspectos relevantes das condições de produção do texto, o reconhecimento do gênero e/ou do tipo de texto em jogo, por exemplo. Por outro lado, foram comuns atividades que exploraram a compreensão global, a localização de informações explícitas, a inferência de informações implícitas.

Convêm ressaltar que o apostilado não apresenta atividades meramente decodificadoras. A capacidade de decodificação costuma ser "mal vista", já que, em geral, o que se coloca é que decodificar é o

\footnotetext{
${ }^{16}$ Hipotetizo que essa abordagem não ocorreu pelo fato de o apostilado, como dito algumas vezes, ignorar o eixo da oralidade. 
menos importante durante o ato de ler. Seria bom rever essa consideração, uma vez que a decodificação não deve ser esquecida das aulas de leitura ou totalmente criticada. Segundo Silva (2004), é evidente que é imprescindível decodificar para depois construir o sentido daquilo que se lê. A interpretação só acontece se ao leitor forem oferecidas condições para reconhecer as palavras escritas (decodificação), fazer a relação delas com o seu sentido, efetuar a combinação desses elementos em estruturas, combinar estratégias cognitivas para captar o sentido do texto e, finalmente, interpretá-lo, fazendo uso das demais capacidades de leitura que o auxiliarão a entender o texto, tornando explícitas as ideias implícitas e obscuras.

Um aspecto negativo no apostilado diz respeito ao desfavorecimento de experiências significativas de leitura pela total ausência de definição de objetivos para as atividades apresentadas. Houve, ainda, uma ausência de inserção do texto em seus contextos sócio-históricos de produção, bem como uma baixíssima exploração dos recursos linguístico-textuais que promovem a construção da textualidade.

Faltou também dar mais atenção ao professor. Seu livro tão somente traz as respostas das questões apresentadas, faltando, ao longo das atividades, orientações metodológicas de como aproveitá-las para explorar outros aspectos que não somente o que foi enfatizado pela questão. Por fim, o sistema desconsidera a articulação que deve existir entre os eixos oralidade, leitura, escrita e análise linguística.

A partir dos resultados aqui apresentados, espero que isso reflita não só em melhorias na elaboração de materiais de ensino, mas também num ensino-aprendizagem de leitura e interpretação de texto melhor, que trará contribuições significativas para o(s) letramento(s) do aluno.

\section{Referências}

BAKHTIN, Mikhail. Os gêneros do discurso. In: . Estética da criação verbal. São Paulo: Martins Fontes, 1979. p. 277-326. [195253] 
BAKHTIN, Mikhail; VOLOCHINOV, Valentin N. Marxismo $e$ filosofia da linguagem. São Paulo: Hucitec, 1981. [1929]

BRASIL. Ministério da Educação. Lei no 9.394/96 - Lei de Diretrizes e Bases da Educação Nacional. Brasília, DF, 1996. Disponível em: <www.planalto.gov.br>. Acesso em: 25 jun. 2011.

BRASIL/MEC/SEB/FNDE. Catálogo do Programa Nacional do Livro Didático para o Ensino Médio: língua portuguesa. Brasília, DF: Ministério da Educação; Secretaria de Educação Básica; Fundo de Desenvolvimento da Educação, 2008. 136 p.

CAGLIARI, Luiz Carlos. Alfabetização e linguística. 10. ed. São Paulo: Scipione, 1997.

CARVALHO NETO, Cassiano Zeferino. O apostilismo. In: . $E$ agora, professor? Por uma pedagogia vivencial. São Paulo: Instituto para a Formação Continuada em Educação (IFCE), 2004. Disponível em: <http://ifce.com.br/php/artigo_mostra.php?cod=22>. Acesso em: 30 set. 2008.

DIAS, Nathália Saliba; LIMA, Robson. Apostila do sistema Positivo de ensino - língua portuguesa: $1^{\mathrm{a}}, 2^{\mathrm{a}}, 3^{\mathrm{a}}$ séries. Curitiba: Editora Positivo, 2008.

DOLZ, Joaquim; SCHNEUWLY, Bernard. Gêneros e progressão em expressão oral e escrita: elementos para reflexões sobre uma experiência suíça (francófona). In: SCHNEUWLY, Bernard et al. Gêneros orais e escritos na escola. Campinas: Mercado de Letras, 2004. p. 41-70. [1996]

DOLZ, Joaquim; SCHNEUWLY, Bernard; DE PIETRO, Jean François. Relato da elaboração de uma sequência: o debate público. In: SCHNEUWLY, Bernard et al. Gêneros orais e escritos na escola. Campinas: Mercado de Letras, 2004. p. 247-276. [1998]

DOLZ, Joaquim; NOVERRAZ, Michèle; SCHNEUWLY, Bernard. Sequências didáticas para o oral e a escrita: apresentação de um 104 Horizontes de Linguística Aplicada, ano 10, n. 2, jul./dez. 2011 
procedimento. In: SCHNEUWLY, Bernard et al. Gêneros orais $e$ escritos na escola. Campinas: Mercado de Letras, 2004. p. 95-128. [2001]

GOLDER, Carolina. Le développement du discours argumentatif. Paris: Delachaux et Niestlé, 1996.

INDURSKY, Freda. Estudos da linguagem: a leitura sob diferentes olhares teóricos. In: TFOUNI, Leda Verdiani (Org.). Letramento, escrita e leitura: questões contemporâneas. Campinas: Mercado de Letras, 2010. p. 163-178.

ISTOÉ. São Paulo: Ed. Três, a. 34, n. 2.132, p. 29, set. 2010.

LIMA, Raimundo de. Escola Apostilada: ilusão ou barbárie? Revista Espaço Acadêmico, n. 63, ago. 2006. Disponível em: <http://www.espacoacademico.com.br/063/63lima.htm>. Acesso em: 18 mar. 2010.

MARCUSCHI, Luiz Antônio. Compreensão de texto: algumas reflexões. In: DIONÍSIO, Ângela Paiva; BEZERRA, Maria Auxiliadora (Orgs.). O livro didático de português: múltiplos olhares. Rio de Janeiro: Lucerna, 2003.

POERSCH, José Marcelino. Pode-se alfabetizar sem conhecimentos de linguística? In: Porto Alegre: Sagra, 1990.

ROJO, Roxane Helena Rodrigues. Letramento e capacidades de leitura para a cidadania. São Paulo: Rede do Saber; CENP; SEE-SP, 2004. (Texto de circulação restrita.)

. Letramentos múltiplos, escola e inclusão social. São Paulo: Parábola Editorial, 2009.

SILVA, Sílvio Ribeiro da. Leitura em língua materna na escola: por uma abordagem sócio-interacional. Trabalhos em Linguística Aplicada, Campinas-SP, v. 1, n. 43, p. 69-81, 2004.

Horizontes de Linguística Aplicada, ano 10, n. 2, jul./dez. 2011 
Sistematização dos conhecimentos propostos pelo apostilado

SOLÉ, Isabel. Estratégias de leitura. 6. ed. Porto Alegre: ArtMed, 1998.

TREDICI, Tompson Carlos. Adoção pelos municípios do estado de São Paulo de contratações de "sistemas apostilados de ensino" de empresas privadas para aplicação nas escolas públicas municipais. São Paulo, 2007. Disponível em: <www.tce.sp.gov.br/artigos/ArtPublicTompsonGestaoDemocEscolaSi stemaApostilado.pdf> Acesso em: 30 set. 2008.

Recebido em: $\quad 21 / 09 / 2011$

Aceito em: $\quad 30 / 01 / 2012$

Title: The systematization of knowledge proposed by "Sistema Positivo" high school's book for reading and interpretation 